\title{
UPPP combined with radiofrequency thermotherapy of the tongue base for the treatment of obstructive sleep apnea syndrome
}

Emke van den Broek • Wietske Richard •

Harm van Tinteren $\cdot$ Nico de Vries

Published online: 20 September 2008

(C) Springer-Verlag 2008

\section{Erratum to: Eur Arch Otorhinolaryngol DOI 10.1007/s00405-008-0640-x}

The third sentence of the second paragraph in "Discussion" should read:

Adding RFTB to UPPP gave an increase in objective success rate of $17.2 \%$, from 37.9 to $55.1 \%$ for Friedman stage II patients and an increase of $24.9 \%$, from 8.1 to $33.0 \%$ for stage III patients.

The online version of the original article can be found under doi:10.1007/s00405-008-0640-x.

E. van den Broek · W. Richard · N. de Vries $(\square)$

Department of Otorhinolaryngology, Head and Neck Surgery,

St. Lucas Andreas Hospital, Jan Tooropstraat 164,

1061 AE Amsterdam, The Netherlands

e-mail: n.vries@slaz.nl

E. van den Broek

e-mail: emke_broek@hotmail.com

H. van Tinteren

Department of Biostatistics,

Antoni van Leeuwenhoek Hospital,

Amsterdam, The Netherlands 